Check for updates

Cite this: RSC Adv., 2017, 7, 42329

Received 20th July 2017

Accepted 29th August 2017

DOI: $10.1039 / \mathrm{c} 7 \mathrm{ra0} 8038 \mathrm{~g}$

rsc.li/rsc-advances

\section{Probing the application of a zirconium coagulant in a coagulation-ultrafiltration process: observations on organics removal and membrane fouling}

\begin{abstract}
Zhaoyang Su, ${ }^{a}$ Xing Li, (D) *a Yanling Yang ${ }^{a}$ and Yiran Fan ${ }^{b}$
Much attention has been paid to coagulation as a pretreatment for controlling membrane fouling. Until now, however, there has been no literature available on the application of Zr-based coagulants in the coagulation-ultrafiltration process. The aim of this work is therefore to investigate the coagulation behavior of $\mathrm{ZrOCl}_{2}$ and its influence on membrane fouling, in comparison with that of the commonly used $\mathrm{Al}$-based coagulants, $\mathrm{Al}_{2}\left(\mathrm{SO}_{4}\right)_{3}$ and $\mathrm{PACl}$. Floc formation kinetics were studied via 'a turbidity fluctuation technique' (PDA measurement). A variation in the $\mathrm{pH}$ and temperature of raw water was also considered in order to test the performance of the three targeted coagulants. The results indicated that the best coagulation efficiency was achieved with the $\mathrm{Zr}$ coagulant, under neutral $\mathrm{pH}$ conditions and at a room temperature of $25{ }^{\circ} \mathrm{C}$. This coagulant resulted in minimum turbidity (0.72 NTU) and the lowest concentration of the supernatant at $\mathrm{UV}_{254}\left(0.005 \mathrm{~cm}^{-1}\right)$; the corresponding values for $\mathrm{Al}_{2}\left(\mathrm{SO}_{4}\right)_{3}$ were $2.79 \mathrm{NTU}$ and $0.011 \mathrm{~cm}^{-1}$, respectively, while those for $\mathrm{PACl}$ being $6.78 \mathrm{NTU}$ and $0.015 \mathrm{~cm}^{-1}$. The flocs obtained by the addition of this $\mathrm{Zr}$ coagulant were larger in size and had superior strength, recovery potential and settleability. In addition, membrane fouling was apparently alleviated through use of the $\mathrm{Zr}$ coagulant, especially in terms of the irreversible fouling, followed by $\mathrm{PACl}$ and $\mathrm{Al}_{2}\left(\mathrm{SO}_{4}\right)_{3}$. The superior removal efficiency of low-medium MW HA may be a plausible explanation for this phenomenon. Particularly, this work describes a novel $\mathrm{Zr}$ coagulant as an important potential candidate for application to the coagulation-ultrafiltration process in the future.
\end{abstract}

\section{Introduction}

Coagulation is considered as an indispensable step to be adopted prior to filtration (e.g., sand filtration and membrane separation), because it allows for the effective removal of particulates and natural organic matters (NOM). ${ }^{1}$ Particulates in source water are destabilized by the addition of positively charged coagulants, and they aggregate to larger flocs during random collision, which is usually driven by mechanical agitation. ${ }^{2}$ The removal of NOM depends on the direct precipitation of NOM-flocs and/or adsorption onto metal hydroxide precipitates. ${ }^{3}$ In this process, selection of the coagulant is of significant importance since the coagulation performance is significantly determined by several related factors, such as speciation of the hydrolysis products of coagulant, as well as the quantity and reactivity of the complexing ligands. ${ }^{3}$ Based on this principle, aluminum (Al) salt coagulants have been widely used during the portable water production for nearly a century. ${ }^{4,5}$ Recent works have, however, reconsidered the

${ }^{a}$ College of Architecture and Civil Engineering, Beijing University of Technology, No. 100 Xi Da Wang Road, Chao Yang District, Beijing 100124, P. R. China. E-mail: SZY_BJUT@163.com; lixingsci@163.com; lixing@bjut.edu.cn; Tel: +861067391726 ${ }^{b}$ Department of Civil and Environmental Engineering, Imperial College London, South Kensington Campus, London SW7 2AZ, UK suitability of Al-based salt coagulants, advising that an excess of residual $\mathrm{Al}$ presented in the effluent could present many drawbacks. In this regard, the elevated concentration of $\mathrm{Al}$ in purified water may lead to poor turbidity removal performance, low disinfection efficiency and a loss in hydraulic capacity. ${ }^{6}$ Also of concern are the effects of the long-term ingestion of water containing high concentrations of $\mathrm{Al}$, which may result in neurological disorders (including Alzheimer's disease) in humans. ${ }^{7}$

Attention has therefore gradually shifted toward the use of economically and environmentally friendly alternatives. The application of Ti-based salts as coagulants has attracted much attention in recent years, ${ }^{\mathbf{8 - 1 0}}$ with Zr-based salt also being recommended as a potential feasible coagulant. Jarvis et al. comparatively evaluated salt coagulants in terms of NOM removal efficiency. ${ }^{11}$ The results showed that the $\mathrm{Zr}$ salt lead to a reduction of $46 \%$ to $150 \%$ dissolved organic carbon (DOC), as compared to the Fe salt. In addition, flocs formed by the $\mathrm{Zr}$ salt were larger in size $(930 \mu \mathrm{m})$ as compared to Fe-flocs $(710 \mu \mathrm{m})$. Hussain et al. indicated that zirconium tetrachloride was more effective for the removal of low-medium molecular weight organics, which could limit the formation of disinfection byproducts (DBPs) often known to be carcinogenic. ${ }^{12,13}$ Besides, Zr salt was also confirmed to be effective for arsenic removal, ${ }^{\mathbf{1 4}}$ and in the treatment of paper and pulp wastewater. ${ }^{15}$ 
What also worth to be noticed is organic membrane fouling, since it hinders the widespread application of membrane techniques during surface water treatment. ${ }^{\mathbf{1 6 , 1 7}}$ Coagulation provides an important avenue for the control of membrane fouling. Ma et al. pointed out that the dosage of coagulant should be carefully considered, because it has been verified that a critical dose of $\mathrm{Al}$ exists which could cause dramatic flux reduction. ${ }^{18}$ Liu et al. successfully mitigated organic membrane fouling caused by humic acid in the long-term by employing a two-stage dose strategy. ${ }^{19}$ Additionally, coagulation coupled with an oxidative technique (e.g. ferrate, ${ }^{20} \mathrm{UV}$ irradiation $^{21}$ and ozone ${ }^{22}$ ) has been confirmed to be more effective in alleviating the reduction of transmembrane pressure (TMP) during ultrafiltration. Recently, attempts have been made to explore the possibility of using novel coagulants to control membrane fouling. ${ }^{23,24}$ Huang et al. verified that the application of titanium sulfate in coagulation can lead to the slightest membrane fouling compared with $\mathrm{Al}$ and Fe salts. ${ }^{23}$ However, until now, there is no report on the feasibility of Zr-based coagulants for the control of membrane fouling.

Therefore, the objective of this study is to evaluate the coagulation efficiency of a novel coagulant, zirconyl chloride octahydrate, and use it to made an attempt to mitigate membrane fouling during the ultrafiltration process. To further understand the coagulation behavior of the $\mathrm{Zr}$ salt coagulant, flocs formation was monitored using a photometric dynamic analysis (PDA) measurement, and their characteristics were also investigated in this study, in comparison with those of the commonly used Al-based metal coagulants, aluminum sulfate $\left(\mathrm{Al}_{2}\left(\mathrm{SO}_{4}\right)_{3}\right)$ and polyaluminum chloride (PACl).

\section{Materials and methods}

\subsection{Chemical reagents}

All the chemicals used in this study were analytical grade except for those specifically mentioned, and stock solutions were prepared using Millipore-Q deionized (DI) water. As reported, humic acid (HA, Sigma-Aldrich, USA) and kaolinite (Fuchen, Tianjin, China) were usually selected as the representatives of the typical organic substances and particulates presenting in the surface water. ${ }^{25,26}$ The preparation of HA and kaolin stock solutions are similar to those reported in the ref. 19 and 26 And the final concentration of HA and kaolin stock solutions in this work were determined to be $10 \mathrm{~g} \mathrm{~L}^{-1}$ and $50 \mathrm{~g} \mathrm{~L}^{-1}$ respectively.

Aluminum sulfate $\left(\mathrm{Al}_{2}\left(\mathrm{SO}_{4}\right)_{3} \cdot 18 \mathrm{H}_{2} \mathrm{O}\right.$, Aladdin, China), polyaluminum chloride (PACl, Fuchen, Tianjin, China) and zirconyl chloride octahydrate $\left(\mathrm{ZrOCl}_{2} \cdot 8 \mathrm{H}_{2} \mathrm{O}\right.$, Aladdin, China) were employed as coagulants, and each stock solution was prepared at a concentration of $0.2 \mathrm{M}$, calculated from the metal element. And the $\mathrm{B}([\mathrm{OH}] /[\mathrm{Al}])$ value of $\mathrm{PACl}$ used in this work is 2.0, comprising $21.5 \% \mathrm{Al}_{\mathrm{a}}, 37.9 \% \mathrm{Al}_{\mathrm{b}}$ and $40.6 \% \mathrm{Al}_{\mathrm{c}}$. Working solutions were prepared before use to avoid the ageing effect. The $\mathrm{pH}$ of the water was adjusted using $0.1 \mathrm{M} \mathrm{NaOH}$ or $\mathrm{HCl}$ solution.

\subsection{Raw water and jar tests}

Raw water was prepared by adding $10 \mathrm{~mL}$ HA stock solution and $6 \mathrm{~mL}$ kaolin stock solution to give $\mathrm{UV}_{254}$ measurements of 0.353 $\pm 0.07 \mathrm{~cm}^{-1}$ and turbidity measurements of $37.8 \pm 1.5$ NTU. Coagulation experiments were performed using a programmable six-paddle blender with $50 \mathrm{~mm} \times 40 \mathrm{~mm}$ flat paddle impeller (ZR4-6, Zhongrun instrument company, Shenzhen, China). Coagulant was dosed after the initial flash mixing (350 $\mathrm{rpm}$ ) of $30 \mathrm{~s}$ for blending raw water $(1 \mathrm{~L})$, followed by $1 \mathrm{~min}$ rapid mixing (300 rpm) for coagulant hydrolyzation, slow mixing $(60 \mathrm{rpm}$ ) of $15 \mathrm{~min}$ for flocs growth and $15 \mathrm{~min}$ for quiescent settlement. After settling, $150 \mathrm{~mL}$ supernatant was collected from sample outlet $3.0 \mathrm{~cm}$ below the water surface. Coagulation efficiency, indicated by the effluent quality, was evaluated based on the measurement of turbidity and UV absorbance of supernatant at $254 \mathrm{~nm}$. The $\mathrm{pH}$ of the raw water was maintained at 7 and the temperature was maintained at $25{ }^{\circ} \mathrm{C}$, otherwise specified (Section 3.2). For better reproducibility, all the coagulation experiments were conducted in triplicate, and the average values were used.

In particular, in order to investigate floc strength and recovery ability, an increased mixing speed of $300 \mathrm{rpm}$ lasting 1 min was introduced to break the fully formed flocs after 15 min flocculation period, and then a slow mixing of $60 \mathrm{rpm}$ for $15 \mathrm{~min}$ was applied to evaluate the recovery ability of broken flocs.

\subsection{PDA monitoring and flocs images}

The kinetics of flocs formation, breakage, and subsequent regrowth were measured by the 'turbidity fluctuation method' using an intelligent photometric dispersion analyzer (iPDA 2000, Rank Brothers, UK). The procedure is similar to that reported by $\mathrm{Yu}$ et $a{ }^{25}{ }^{25}$ Two indexes including the average transmitted light intensity (dc value) and the root mean square (rms) value of the fluctuating component of the intensity were monitored. The ratio ( $\mathrm{rms} / \mathrm{dc}$ ) was outputted and defined as the flocculation index (FI), which allows for sensitive measurement of particles aggregation. ${ }^{27}$ The FI value is strongly correlated with the floc size, and it increases as the flocs grow. ${ }^{28}$ Particularly the strength and recovery factor can be quantified by the change of FI value, as displayed in the eqn (1) and (2). Additionally, the growth rate of flocs can be also evaluated by the increasing rate of FI value during the initial flocculation stage. The data were recorded using a data acquisition system (Pico ADC-11, Pico Technology, UK) every 2 seconds after the initial FI value was maintained at a steady rate.

$$
\begin{gathered}
\left.F_{1}=\frac{V_{2}}{V_{1}} \text { (strength factor }\right) \\
\left.F_{2}=\frac{V_{3}-V_{2}}{V_{1}-V_{2}} \text { (recovery factor }\right)
\end{gathered}
$$

where $V_{1}$ is the maximum FI value before floc breakage; $V_{2}$ is the minimum FI value when flocs are broken, and $V_{3}$ is the maximum FI value after regrowth of broken flocs.

Coagulation performance is largely determined by flocs characteristics, such as floc size, fractal dimension, and 
density. ${ }^{29}$ To investigate these characteristics, flocs were carefully withdrawn using a hollow glass tube (inner diameter of $2.5 \mathrm{~mm}$ ), after they have been fully formed, and then slowly transferred to a glass slide. Flocs images were captured using a CCD camera (MVEM510C/M, Microvision, China) equipped with a lens (BT-2307, Microvision, China). These images had a resolution of $2456 \times$ 2058 pixels, where 1 pixel represents $3.45 \mu \mathrm{m}$. Open-access software (Image 1.48 ) was used to further analyze the flocs images. The two-dimensional fractal dimension is defined by a power law relationship between the projected area (As) and the characteristic length of the floc, denoted as "l". It can be calculated from:

$$
\text { As } \sim l^{D_{2}}
$$

where $D_{2}$ is the two-dimensional fractal dimension. The value of $D_{2}$ ranges from 1 to 2 , a smaller value of 1 represents a linear shape, while a larger value of 2 indicates a spherical floc. ${ }^{30}$

\subsection{UF experiments and membrane fouling analysis}

Ultrafiltration (UF) experiments were conducted in dead-end mode using a filtration cell (Amicon 8400, Millipore, USA) at room temperature $\left(25 \pm 1{ }^{\circ} \mathrm{C}\right)$. A flat sheet membrane (PALL, USA) of polyethersulfone (PES) was used in this study, with a molecular weight cut-off (MWCO) of $100 \mathrm{kDa}$. Prior to testing, each membrane was soaked in Millipore-Q DI water for at least $12 \mathrm{~h}$, and then washed thoroughly for the removal of organic residues on the PES membrane. During filtration, a constant pressure was provided by nitrogen gas and maintained at 0.1 MPa. Membrane fouling was evaluated using an index known as 'normalized flux', defined as $J / J_{0}$, where $J$ is the real-time flux and $J_{0}$ corresponds to the initial flux. The permeate flux was calculated according to the change in the weight of filtrate which was measured using an electronic balance (MSU5201S-000-D0, Sartorius AG, Germany). And the data was automatically recorded every 2 seconds by an open software (Version 1.0.5, Future Co. Ltd, China) using a personal computer. The overall setup of the UF experiment system applied in this work was similar to that employed by other researchers. ${ }^{31}$

The filtration experiment in this study includes 2 cycles: continuous filtration of $600 \mathrm{~mL}$ coagulated water without settlement, and backwashed by $200 \mathrm{~mL}$ DI water; the next cycle begins with the filtration of $300 \mathrm{~mL}$ coagulated water without backwashing process. In most cases, membrane fouling is generally elucidated by and classified into irreversible fouling (IF), reversible fouling (RF) and total fouling (TF). ${ }^{32}$ The relative calculation is expressed in the following equation:

$$
\begin{gathered}
\mathrm{IF}_{n}=\frac{J_{0}-J_{\mathrm{p}(n+1)}}{J_{0}} \\
\mathrm{TF}_{n}=\frac{J_{0}-J_{\mathrm{f}(n)}}{J_{0}} \\
\mathrm{RF}_{n}=\mathrm{TF}_{n}-\mathrm{IF}_{n}
\end{gathered}
$$

where ' $J_{\mathrm{p}(n)}$ ' is the initial membrane flux, ' $\mathrm{J}_{\mathrm{f}(n)}$ ' is the final flux, and ' $n$ ' represents the operation cycle of $\geq 1$.

\subsection{Other analytical methods}

To understand the characteristics of electric charge of impurities under different coagulant dosages, flocs were withdrawn instantly after the rapid mixing period, and zeta potentials were examined for 3 times by Zetasizer (Zetasizer 2000, Malvern, UK). The UV absorbance at $254 \mathrm{~nm}\left(\mathrm{UV}_{254}\right)$ of $0.45 \mu \mathrm{m}$ filtered sample was determined using an ultraviolet/visible spectrophotometer (UV2600, Shunyu, Shanghai, China). pH was measured by a pH meter (PHSJ-3F, Leici, Shanghai, China). Molecular weight (MW) distribution of organic matters in the raw water and the treated water were analyzed according to the procedure as reported in the ref. 33. All the measurements were carried out in triplicate, and the average values were adopted.

In order to study the surface morphology of fouled membrane, the used membrane sheet was placed in a dryer until it has been fully dried. The dried membrane was carefully cut into $1 \mathrm{~cm} \times 1 \mathrm{~cm}$ fragment and then platinum-coated on a sample plate for observation under scanning electron microscopy (SEM, S4800, Hitachi, Japan).

\section{Results and discussion}

\subsection{Zeta potential and coagulation behavior}

A series of coagulation trials were undertaken in order to obtain a preliminary understanding of coagulation performance of the three coagulants (i.e. $\mathrm{ZrOCl}_{2}, \mathrm{Al}_{2}\left(\mathrm{SO}_{4}\right)_{3}$ and $\mathrm{PACl}$ ), without $\mathrm{pH}$ adjustment of the raw water. In this regard, the variation of zeta potential (ZP), turbidity and organics removal efficiency were simultaneously evaluated within the dosage range from $0.02 \mathrm{mM}$ to $0.14 \mathrm{mM}$, as shown in Fig. 1.

Fig. 1a shows the influence of coagulant dosage on the zeta potential of the initial formed flocs which were withdrawn and measured after 1 min rapid mixing for coagulant hydrolyzation and particles destabilization. The $\mathrm{ZP}$ of raw water was determined to be $-32.1 \mathrm{mV}$. It can be seen that the value of $\mathrm{ZP}$ normally kept a positive relationship with the increasing dosage. Particularly, the $\mathrm{ZP}$ of flocs firstly increased to the positive when $\mathrm{Al}_{2}\left(\mathrm{SO}_{4}\right)_{3}$ was added at dosages higher than $0.04 \mathrm{mM}$. Comparatively, for PACl and $\mathrm{ZrOCl}_{2}$, these dosages had to be greater than $0.08 \mathrm{mM}$ and $0.10 \mathrm{mM}$ respectively. Clearly, the sequence of the ability of charge neutralization of three coagulants was as follows: $\mathrm{Al}_{2}\left(\mathrm{SO}_{4}\right)_{3}>\mathrm{PACl}>\mathrm{ZrOCl}_{2}$, which was different with the observations in our previous study. ${ }^{34}$ In the absence of HA in the raw water, the ZP value of flocs reversed to the positive at a lower PACl dosage of $0.025 \mathrm{mM}$, while that for $\mathrm{Al}_{2}\left(\mathrm{SO}_{4}\right)_{3}$ was of $0.08 \mathrm{mM}$. This difference can be explained by the various speciation in the both Al-based coagulants. Specifically, $\mathrm{Al}_{2}\left(\mathrm{SO}_{4}\right)_{3}$ is mainly composed of monomer $\mathrm{Al}\left(\mathrm{Al}_{\mathrm{a}}\right)$; PACl used is mainly polymeric $\mathrm{Al}\left(\mathrm{Al}_{\mathrm{b}}\right.$ and $\mathrm{Al}_{\mathrm{c}}$ ), and more details can be found in Section 2.1. The constituent of $\mathrm{Al}_{\mathrm{b}}$ in $\mathrm{PACl}$ is more stable than $\mathrm{Al}_{\mathrm{a}}$ and more effective in charge neutralization to destabilize kaolin particles. In contrast, the majority of $\mathrm{Al}_{\mathrm{a}}$ in $\mathrm{Al}_{2}\left(\mathrm{SO}_{4}\right)_{3}$ partially hydrolyzes to $\mathrm{Al}_{\mathrm{b}}$ and $\mathrm{Al}_{\mathrm{c}}$ after dosing, and thus complexation with $\mathrm{HA}$ functions simultaneously. Hence, it can be observed that $\mathrm{Al}_{2}\left(\mathrm{SO}_{4}\right)_{3}$ is more effective for the complexation between 

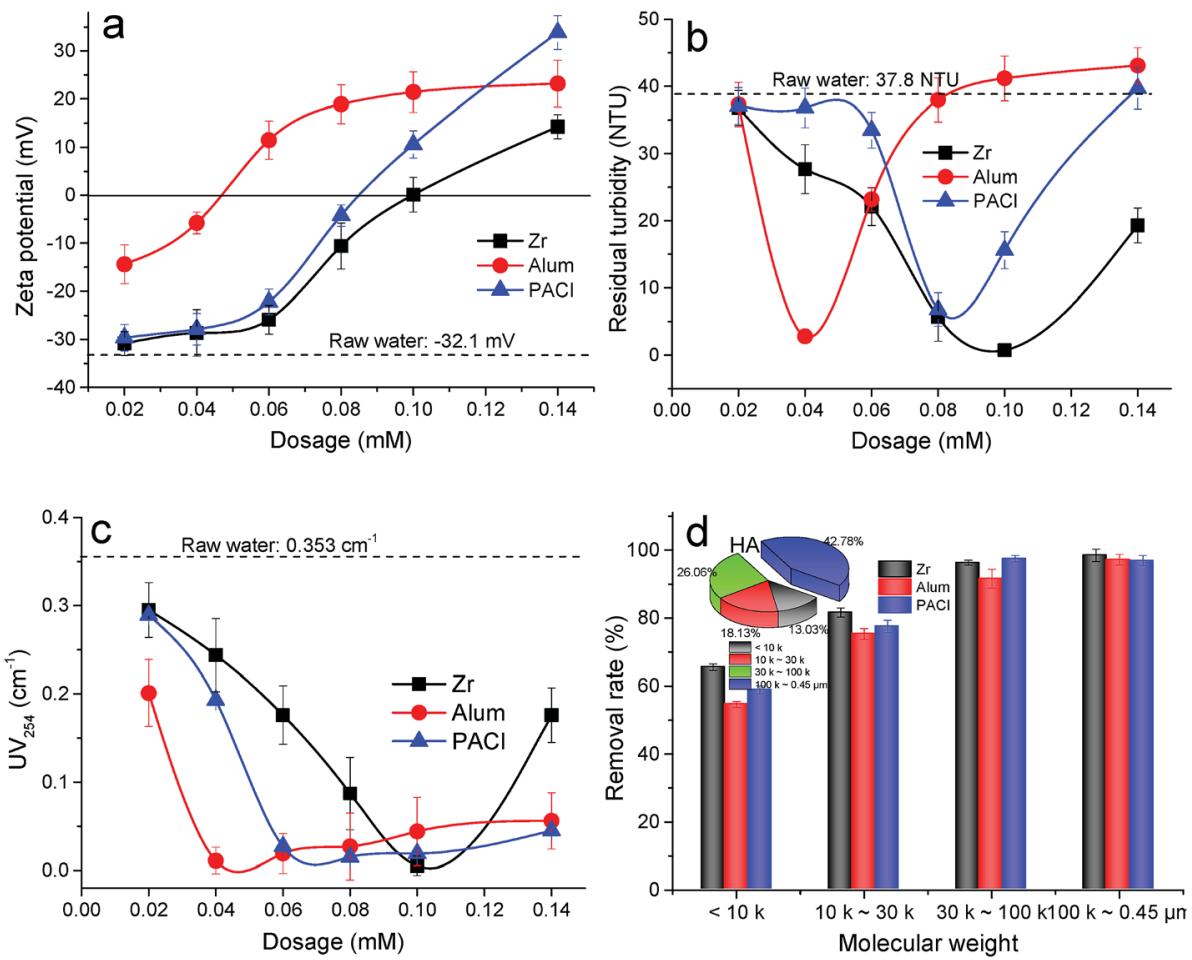

Fig. 1 Effect of different dosages of the three coagulants on: (a) zeta potential, (b) residual turbidity and (c) $U V_{254}$ absorbance; (d) removal of different MW HA constituents under the optimum dosage (samples were collected immediately after rapid mixing for the measurement of zeta potential, and samples of other analyses were collected after settlement).

positively charged metal hydroxide and negatively charged organics, viz. humic acid in this study.

The coagulation performance of the three coagulants was studied in terms of turbidity and organic substance removal, as presented in Fig. $1 \mathrm{~b}-\mathrm{d}$. The turbidity and $\mathrm{UV}_{254}$ absorbance of the raw water were $37.8 \mathrm{NTU}$ and $0.353 \mathrm{~cm}^{-1}$, as achieved by the addition of kaolinite and humic acid. Regarding turbidity removal (Fig. 1b), the optimal dosages of $\mathrm{ZrOCl}_{2}, \mathrm{Al}_{2}\left(\mathrm{SO}_{4}\right)_{3}$ and PACl were found to be $0.10 \mathrm{mM}, 0.04 \mathrm{mM}$ and $0.08 \mathrm{mM}$, respectively. Similarly, superior HA removal were also found at the same dosages of the three coagulants (Fig. 1c). The trend in organics removal was apparently different with that in turbidity removal under a dosage range from $0.02 \mathrm{mM}$ to $0.14 \mathrm{mM}$. Specifically, as to HA removal (Fig. 1c), the residual concentration represented by $\mathrm{UV}_{254}$ absorbance kept at a low level within the dosage range from $0.04 \mathrm{mM}$ to $0.14 \mathrm{mM}$ when the Al-based salt coagulants were employed, whereas turbidity removal performance showed a different trend. This phenomenon can be explained by the different removal mechanisms of organics and particulates. Colloid/particulates destabilization and aggregation is the mechanistic pathway for kaolinite removal; For dissolved organics removal, complexation plays a key role. Hence, it suggests that complexation of organics can be efficient under a broader dosage range of $\mathrm{Al}$ salts, compared to that of particles destabilization. In comparison, the dosage of $\mathrm{ZrOCl}_{2}$ should be better carefully selected for the expected performance, since higher or lower dosages other than $0.10 \mathrm{mM}$ can cause obvious negative effects (Fig. $1 \mathrm{~b}$ and c). Also in the recent studies on the application of titanium-based (Ti-based) coagulants, Chekli et al. found polytitanium tetrachloride and titanium tetrachloride had broader region of good flocculation in terms of coagulant dose, compared with $\mathrm{FeCl}_{3}$ coagulant. ${ }^{10,35}$ And a comparative study on the Zr-based and Ti-based coagulants in the future would be interesting. Additionally, as shown in Fig. $1 \mathrm{~d}, \mathrm{ZrOCl}_{2}$ exerted a better removal efficiency of lowmedium MW humic substances ( $<100 \mathrm{kDa})$, compared with Al-based coagulants. This result was also confirmed by other researcher previously. ${ }^{36}$ Hence, for clarity, the optimum dosages of $\mathrm{ZrOCl}_{2}, \mathrm{Al}_{2}\left(\mathrm{SO}_{4}\right)_{3}$ and $\mathrm{PACl}$ were determined to be $0.10 \mathrm{mM}$, $0.04 \mathrm{mM}$ and $0.08 \mathrm{mM}$ respectively, and were employed throughout the following experiments.

\subsection{Effects of $\mathrm{pH}$ and temperature on coagulation efficiency}

Both significant factors including $\mathrm{pH}$ and temperature determining the coagulation performance were also considered in this study (Fig. 2). At a pH of 5, as shown in Fig. 2a, the organics removal efficiency of the three coagulants were all slightly reduced (compared with a pH of 7 , Fig. 2e), and maintained beyond $80 \%$. Nevertheless, an improved removal efficiency of organic matter was observed in the previous study when the $\mathrm{pH}$ value decreased from 7 to 6 in Al-based coagulation system. ${ }^{37}$ This phenomenon can be attributed to the different hydrolysis degree of $\mathrm{Al}$ salt under various $\mathrm{pH}$ values. At a lower $\mathrm{pH}$ of 5 in this work, the polymerization of $\mathrm{Al}^{3+}$ was inhibited at a certain extent, and the adsorptive removal of HA by high polymeric positive hydrolyzates was thus reduced. ${ }^{38}$ The ability to remove turbidity, however, were significantly deteriorated for $\mathrm{ZrOCl}_{2}$ 

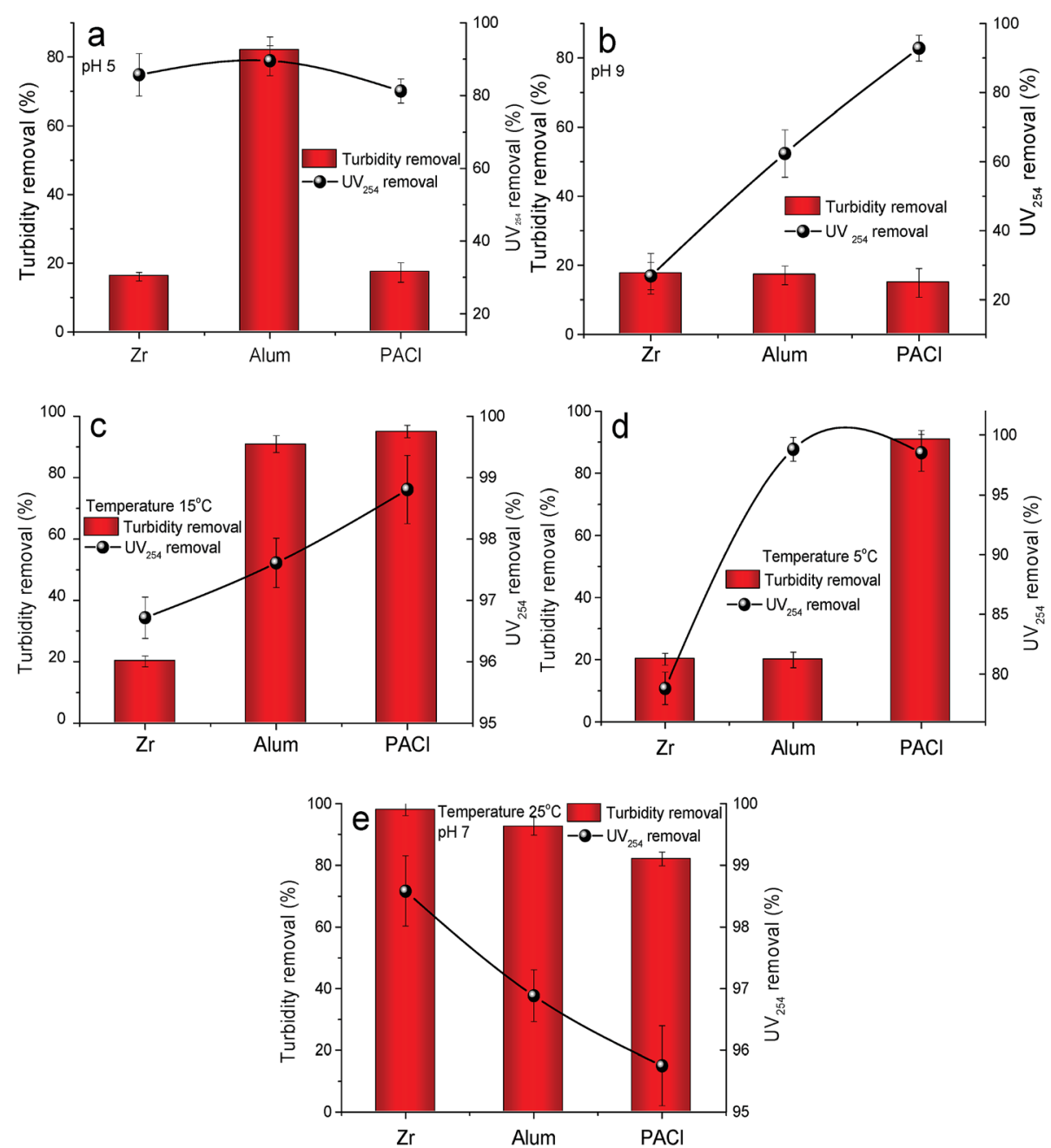

Fig. 2 Effects of $\mathrm{pH}$ and temperature on coagulation efficiency: (a) a $\mathrm{pH}$ value of 5, (b) a pH value of 9, (c) temperature of $15^{\circ} \mathrm{C}$, (d) temperature of $5{ }^{\circ} \mathrm{C}$ and (e) $\mathrm{pH}$ 7and temperature of $25^{\circ} \mathrm{C}$.

and PACl. It was apparent that the relative ideal particulates and $\mathrm{HA}$ removal at $\mathrm{pH} 5$ can be only attained by adding $\mathrm{Al}_{2}\left(\mathrm{SO}_{4}\right)_{3}$. At pH 9, the removal performance of organics was impeded, except for $\mathrm{PACl}$, which maintained at a reduction rate of $92.83 \%$ (Fig. 2b). In terms of turbidity removal, the performance of the three coagulants were all extremely decreased to a removal rate below $20 \%$. It is generally believed that when $\mathrm{pH}$ was higher than 8.0, the suspensions system was difficult to be destabilized since the hydrolyzate were transformed to $\mathrm{Al}(\mathrm{OH})_{4}{ }^{-} \cdot{ }^{38,39}$ While for the used PACl product, the polymeric and colloidal species (i.e. $\mathrm{Al}_{\mathrm{b}}$ and $\mathrm{Al}_{\mathrm{c}}$ ) remained relatively stable after dosing and still obtained ideal treatment performance in HA. Particularly a low removal efficiency in turbidity can be attributed to the poorer settleability of flocs formed in this case, and these flocs (comprising HA, kaolin and hydroxides) were filtered before the measurement of $\mathrm{UV}_{254}$ and thus led to a lower $\mathrm{UV}$ value.

Owing to the fluctuation of temperature of source water seasonally, it is possible to gain an in-depth knowledge of the application of coagulants at various temperatures, especially at low temperature which has been confirmed to exert adverse effects on coagulation performance. ${ }^{40,41}$ When the temperature of test water decreased from $25{ }^{\circ} \mathrm{C}$ to $15{ }^{\circ} \mathrm{C}$ (Fig. 2c), the coagulation performance was influenced at varying degree. A significant negative influence on coagulation efficiency of both turbidity and $\mathrm{HA}$ removal was found when $\mathrm{ZrOCl}_{2}$ was added. In comparison, a further decrease of temperature to $5{ }^{\circ} \mathrm{C}$ (Fig. 2d) only exerted slight negative influence on PACl coagulation performance, while the others were greatly deteriorated in terms of turbidity removal. In particular, a relative desirable removal of humic acid (>95\%) can be still obtained by Al-based salt coagulants at a low temperature of $5{ }^{\circ} \mathrm{C}$. It can be found that complexation ability between hydroxides of Al salts and HA showed stronger resistance to the decrease in temperature from $25{ }^{\circ} \mathrm{C}$ to $5{ }^{\circ} \mathrm{C}$. And this result was similar to the other observation. ${ }^{42}$

\subsection{PDA monitoring and flocs characteristics}

To gain further insight into the coagulation behaviors including flocs formation kinetics and their characteristics, a 'turbidity fluctuation' technique (PDA measurement) and flocs photography based on a CCD camera were applied in this work (Fig. 3 
and 4). The dosages of the three coagulants were selected at optimum values, i.e. $0.10 \mathrm{mM}$ for $\mathrm{ZrOCl}_{2}, 0.04 \mathrm{mM}$ for $\mathrm{Al}_{2}\left(\mathrm{SO}_{4}\right)_{3}$ and $0.08 \mathrm{mM}$ for PACl. And more detailed properties of flocs formed by the three coagulants, such as floc size, fractal dimension, settleability as well as strength and recovery factor, were comparatively investigated.

Fig. 3a shows a PDA measurement of the process of flocs formation and the following settlement for $15 \mathrm{~min}$, as indicated by the variation in the FI value. It can be seen clearly that a much higher FI value than the others up to 2.47 was obtained by $\mathrm{Zr}$ salt flocs (Fig. 3a). By contrast, the flocs formed by Albased salt coagulants reached the similar FI value at a lower level of $\sim 1.38$. The difference of floc size between $\mathrm{Zr}$-based and Al-based salt flocs was also verified by the direct observation on the measurements derived from flocs images (Fig. 4a-c). The corresponding result was summarized in Fig. 3b. Specifically, the average size of flocs formed by the $\mathrm{Zr}$ salt was found to be $414.7 \mu \mathrm{m}$, nearly twice that of the $\mathrm{Al}_{2}\left(\mathrm{SO}_{4}\right)_{3}$ and PACl flocs, with average diameters of $185.3 \mu \mathrm{m}$ and $167.8 \mu \mathrm{m}$, respectively. This result kept consistent with the FI values as reflected in Fig. 3a, and a certain deviation within $8 \%$ (caused by different measurement methods) was theoretically permitted. Additionally, the floc size distribution, as shown in Fig. 4d, indicated that the major range of $\mathrm{Zr}$ salt floc size was between 300-500 $\mu \mathrm{m}$, larger than that of $\mathrm{Al}$ salt flocs mainly ranging from $100 \mu \mathrm{m}$ to $200 \mu \mathrm{m}$.

Notably, the flocs formed by the $\mathrm{Zr}$ salt settled much faster than the Al salt flocs, as demonstrated by the rate of the reduction of FI value after 15 min slow mixing (Fig. 3a). This may be attributed to the larger size or more compact flocs formed by the $\mathrm{Zr}$ salt, since the darker flocs displayed in Fig. 4a may suggest a more compact structure and more impurities inside. Besides, the appearance of flocs formed by $\mathrm{Zr}$ salt were more inclined to a circular shape, while that of Al-based salts were more like a linear shape (Fig. $4 \mathrm{a}-\mathrm{c}$ ). This phenomenon was evidently supported by the fractal dimension of $\mathrm{Zr}$ salt flocs (1.73), higher than $\mathrm{Al}_{2}\left(\mathrm{SO}_{4}\right)_{3}$ flocs (1.33) and PACl flocs (1.52).

Compared with flocs settling performance, the growth rate of flocs was also evaluated in this work. The flocs growth rate can be represented by the ratio of the FI value to time, i.e. the slope of FI value curve during the flocs formation period. ${ }^{43}$ It was readily concluded that the highest flocs growth rate was obtained by adding $\mathrm{ZrOCl}_{2}$, then that of PACl, and lastly $\mathrm{Al}_{2}\left(\mathrm{SO}_{4}\right)_{3}$ (Fig. 3a and c). In particular, the strength of flocs formed by the $\mathrm{Zr}$ salt was the highest among the three coagulants used (Fig. 3d), and was also verified by the more compact flocs morphology shown in Fig. 4a. Moreover, a complete recovery of broken $\mathrm{Zr}$ salt flocs was simultaneously found in surprise, compared with the poorer regrowth ability of Al salt flocs (Fig. 3d). It can therefore be concluded that flocs with larger size, faster settleability, higher strength and better recovery potential can be simultaneously obtained through the use of $\mathrm{ZrOCl}_{2}$ as coagulant.

\subsection{Significance of particles in coagulation}

Due to the different removal mechanisms of organic matters and particulates, it is necessary to evaluate the coagulation behaviors of the three targeted coagulants in the absence of kaolinite. Fig. 5a depicts the process of flocs formation in the humic acid system at a $\mathrm{pH}$ of 7 . HA-Zr salt flocs grew faster than the flocs formed by $\mathrm{Al}$ salt coagulants, and attained the highest FI value, approximately 0.68. $\mathrm{HA}$ flocs formed by $\mathrm{Al}_{2}\left(\mathrm{SO}_{4}\right)_{3}$
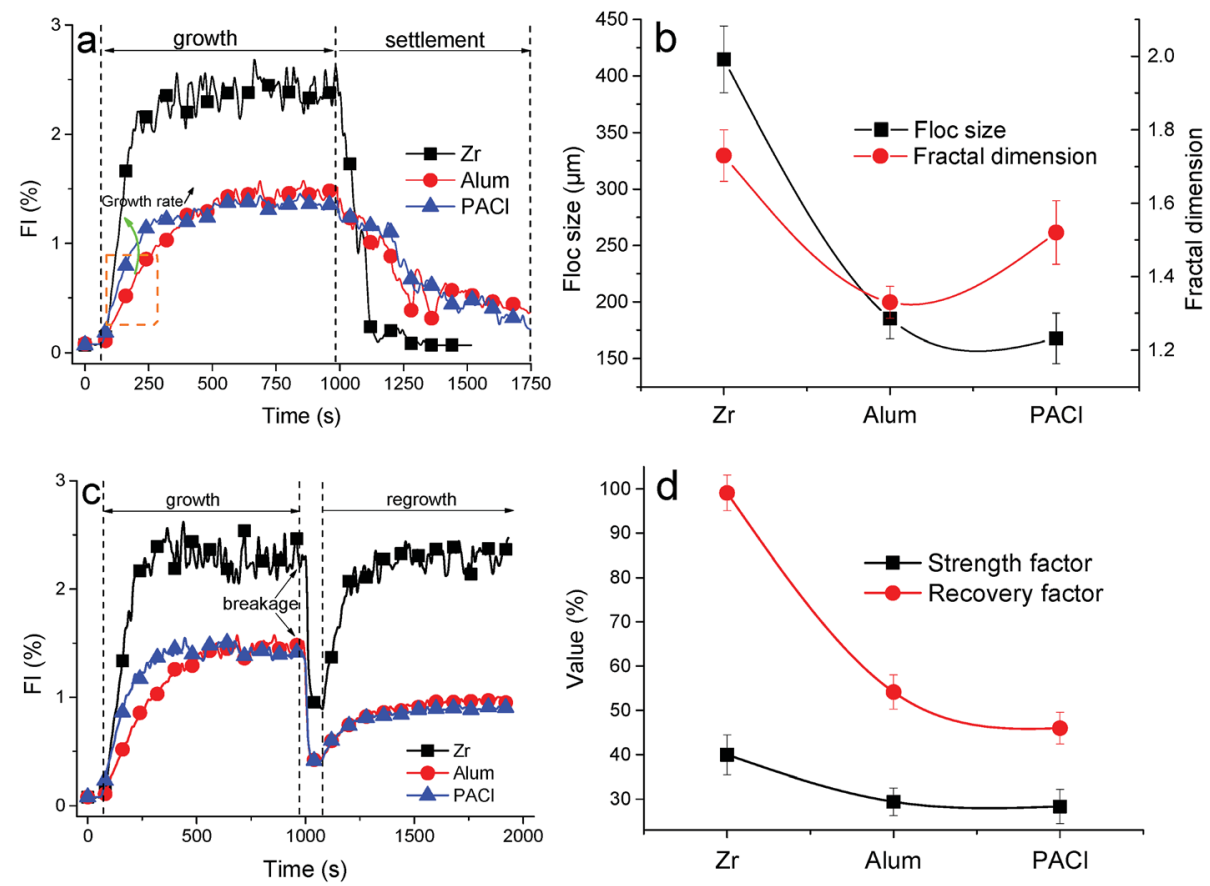

Fig. 3 PDA measurement and flocs characteristics: (a) monitoring on flocs formation and settlement, (b) floc size and its fractal dimension, (c) monitoring on flocs growth, breakage and regrowth and (d) strength and recovery factor of flocs. In (a), floc growth rate indicated by increasing rate of $\mathrm{FI}$ value presented in the red dashed box significantly increases following the sequence of the green arrow. 

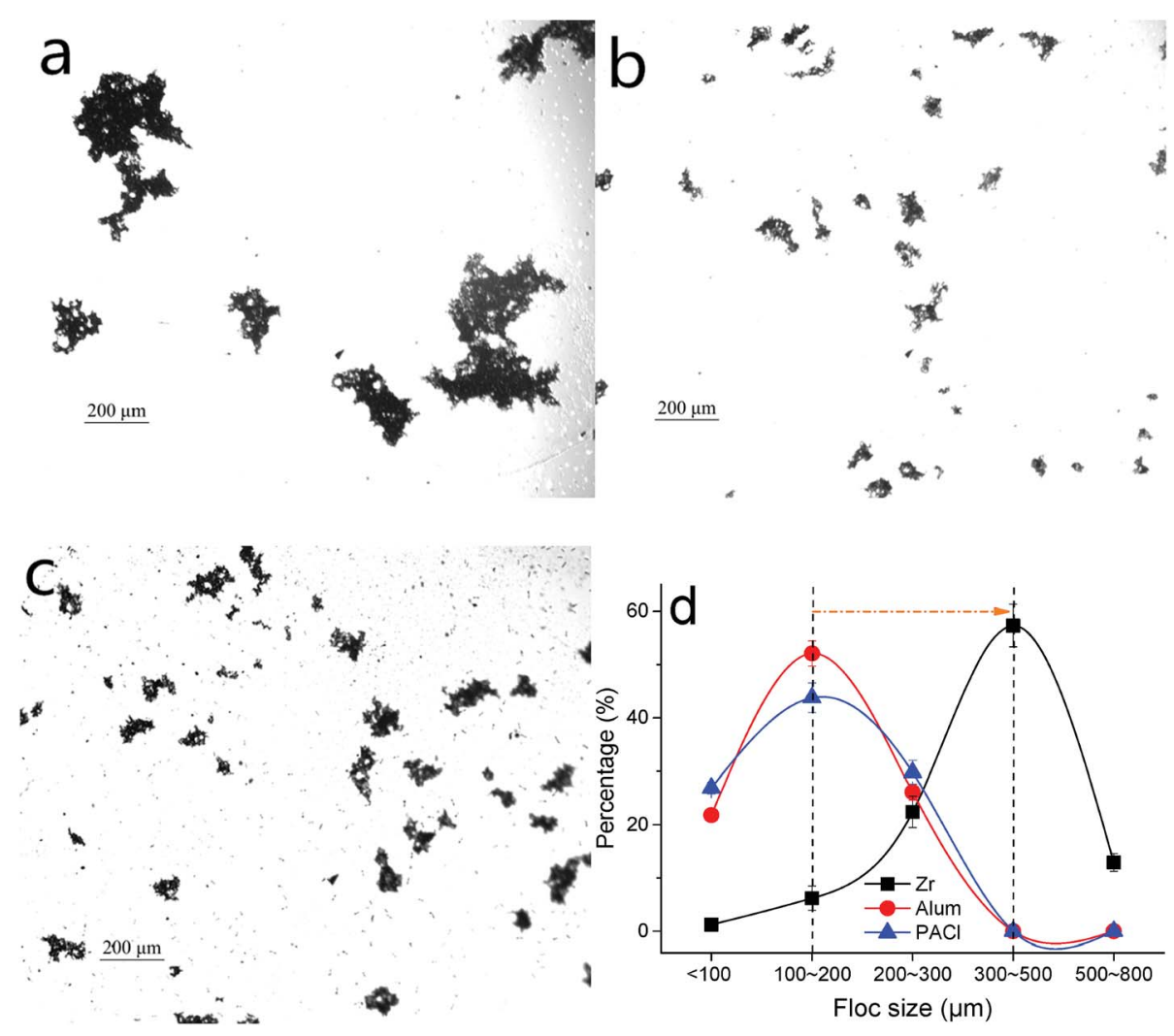

Fig. 4 Flocs images and their size distribution. HA-kaolin raw water coagulated by: (a) $\mathrm{ZrOCl}_{2}$, (b) $\mathrm{Al}_{2}\left(\mathrm{SO}_{4}\right)_{3}$ and (c) PACl; (d) floc size distribution (magnification: $\times 80$; coagulation was conducted at the optimum dosages of the three coagulants respectively; the quantity of floc for size distribution analysis was at least 300).

reached at a lower FI level of $\sim 0.32$. However, the addition of PACl did not contribute to any apparent increase in the FI value, which indicated that there were not visible flocs formed. Also this result was demonstrated by the observations on flocs images (Fig. 5d). Interestingly, the sizes of flocs displayed in Fig. $5 \mathrm{~b}$ and $\mathrm{c}$ were similar to the corresponding flocs formed by HA-kaolin and metal hydroxide shown in Fig. 4b and c separately. In response to the low FI values of HA-flocs, compared with those shown in Fig. 3a, the reason can be explained by the distinctive characteristics of scattered light with or without kaolin particles, which could significantly alter the FI value. And the similar phenomenon was found and explained in the ref. 44 . Therefore, it can be deduced that the larger flocs formed by $\mathrm{Zr}$ salt may be attributed to the greater size of its hydroxide and/or the stronger interaction between these hydroxide/micro-flocs, regardless of the presence of kaolin particles. While particles played an important role during the flocs formation when adding $\mathrm{PACl}$, and the function of particles in this case was more likely to act as the flocculation cores which contributed to the growth of flocs formed by PACl hydroxide.

\subsection{Membrane fouling analysis}

Ultrafiltration experiments were conducted using coagulated water without settlement as feed water under a constant pressure of $0.1 \mathrm{MPa}$. And the coagulation experiments were performed under the optimum dosages of each coagulant

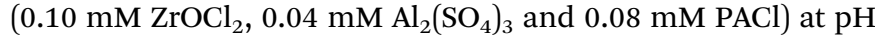
7. The flux decline of membrane was indicated by the variation of normalized flux $\left(J / J_{0}\right)$, as shown in Fig. 6a. It can be noted that the flux decline induced by $\mathrm{Zr}$ salt flocs decreased more quickly at first (the initial filtration volume of $150 \mathrm{~mL}$ ) than that caused by $\mathrm{Al}$ salt flocs. Under the continuous filtration up to a volume of $600 \mathrm{~mL}$ in an operation cycle, flocs formed by $\mathrm{Al}_{2}\left(\mathrm{SO}_{4}\right)_{3}$ led to the worst membrane fouling, as indicated by the final normalized flux $\left(J / J_{0}\right)$ of 0.67 , followed by $\mathrm{PACl}$ and $\mathrm{ZrOCl}_{2}$. This result was partly consistent with the finding of Wang et al. in terms of the membrane fouling caused by $\mathrm{Al}$ salt flocs. ${ }^{45}$ In addition, the flux of membrane fouled by $\mathrm{Zr}$ salt flocs can be recovered to 0.82 after backwashing of $200 \mathrm{~mL}$ DI water. The degree of membrane flux recovery (by hydraulic backwashing) is considered to be dependent on the characteristics of pollutants and membrane, and generally characterized by the two typical fouling modes, including reversible fouling and irreversible fouling. As shown in Fig. 6b, the percentage of reversible fouling of membrane filtered by Zr salt coagulated water was found to be nearly half of its total membrane fouling, while irreversible fouling was more severe when filtered by coagulated water containing $\mathrm{Al}$ salt flocs. In most cases, irreversible fouling is commonly attributed to pore blocking in micro- and ultrafiltration membranes. Wang et al. found that HA of MW fraction of $30-50 \mathrm{kDa}$ could cause the most severe irreversible fouling during ultrafiltration process, followed by the MW fraction of 10-30 kDa and MW 

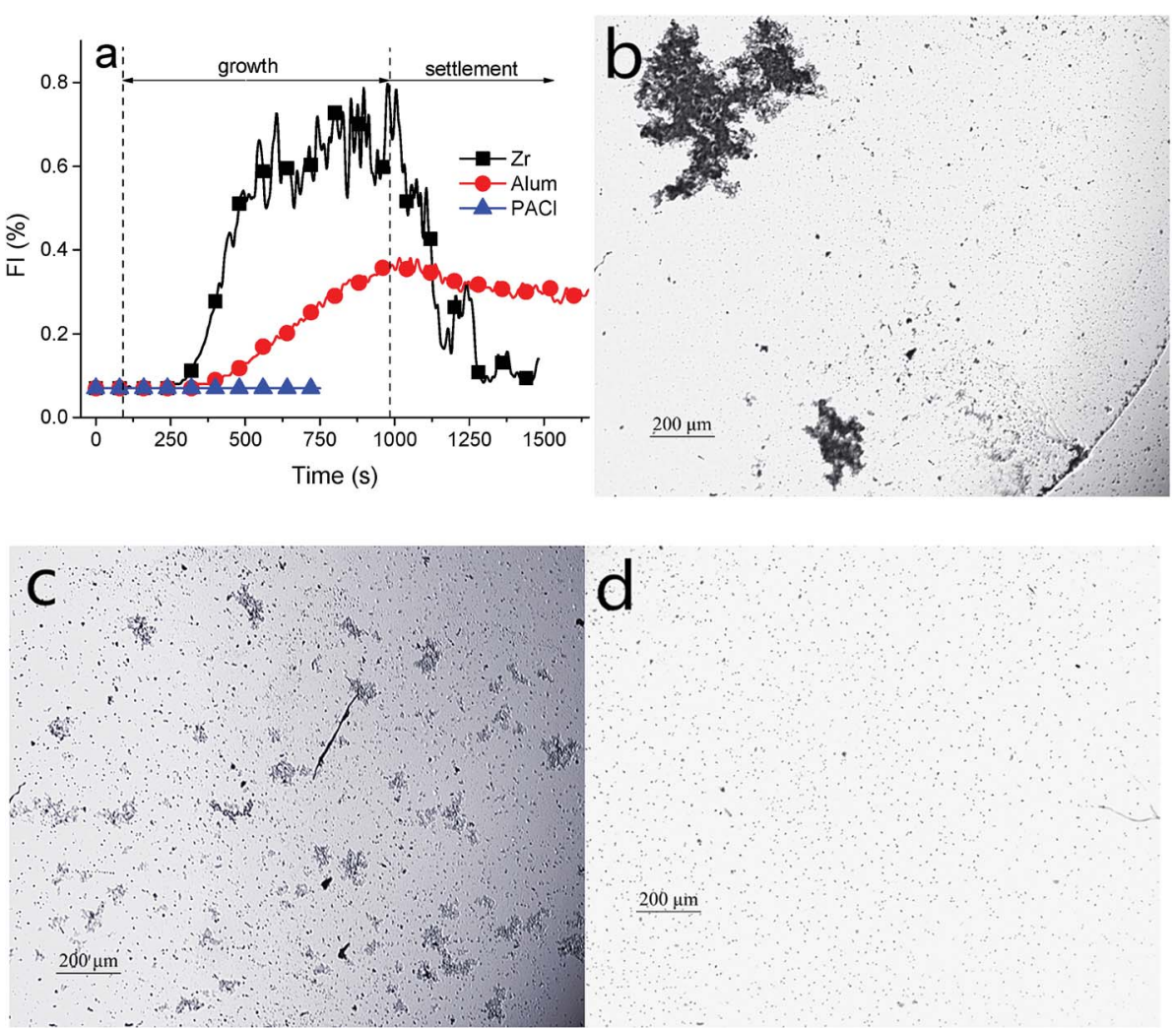

Fig. 5 A comparative investigation on the coagulation performance in the absence of kaolin particles in the raw water. (a) Monitoring flocs formation and settlement using PDA; flocs images of (b) Zr-HA flocs, (c) alum-HA flocs and (d) PACl-HA flocs (magnification: $\times 80$; raw water: $10 \mathrm{mg} \mathrm{L}^{-1} \mathrm{HA}$ under neutral $\mathrm{pH}$; the dosages of $\mathrm{ZrOCl}_{2}, \mathrm{Al}_{2}\left(\mathrm{SO}_{4}\right)_{3}$ and $\mathrm{PACl}$ are $0.10 \mathrm{mM}, 0.04 \mathrm{mM}$ and $0.08 \mathrm{mM}$ respectively).

fraction less than $10 \mathrm{kDa}^{45}$ This finding could also give a feasible explanation for the more severe irreversible membrane fouling caused by $\mathrm{Al}$ salts coagulated water in this study, owing to their lower removal efficiency of HA of low and medium MW fractions, in a comparison with the Zr-based coagulant (Fig. 1d).

SEM images of the fouled membranes were also employed to observe the surface morphology of the cake layer after they have been air-dried (Fig. 7). Compared with the new membrane (Fig. 7a), membranes fouled by $\mathrm{ZrClO}_{2}, \mathrm{Al}_{2}\left(\mathrm{SO}_{4}\right)_{3}$ and $\mathrm{PACl}$ coagulated water were displayed by Fig. $7 \mathrm{~b}-\mathrm{d}$, respectively.
Hydraulic resistance $\left(R_{\mathrm{m}}\right)$, adsorption resistance $\left(R_{\mathrm{a}}\right)$, pore blocking resistance $\left(R_{\mathrm{p}}\right)$ and cake formation resistance $\left(R_{\mathrm{c}}\right)$ are considered as the typical membrane fouling resistance, according to the ref. 46 . Specifically, $R_{\mathrm{c}}$ is mainly determined by the characteristics of cake layer which is formed by the accumulation of deposited flocs. And floc property might be a critical influential factor affecting the formation of cake layer. ${ }^{47} \mathrm{An}$ obvious distinction of cake layer (looser structure) formed by $\mathrm{Zr}$ salt flocs can be found in Fig. 7b, compared with that formed by Al salt flocs (Fig. 7c and d). Accordingly, it can be primarily deduced that surface blocking occurred causing a reduction in
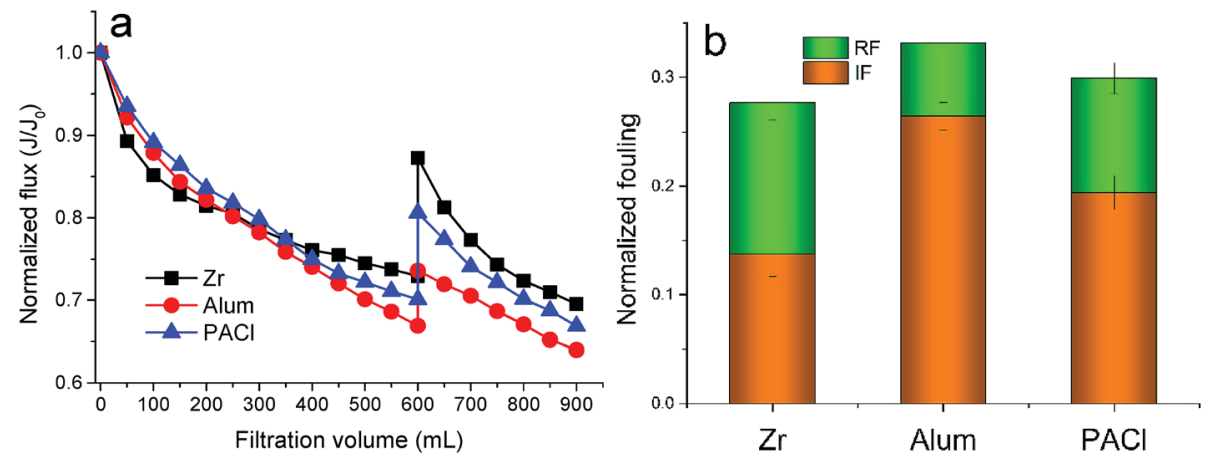

Fig. 6 Ultrafiltration experiments and membrane fouling analysis. (a) Normalized flux decline as a function of filtration volume; (b) analysis of reversible and irreversible fouling. Note: the dosage of each coagulant was selected at the optimum as aforementioned. 

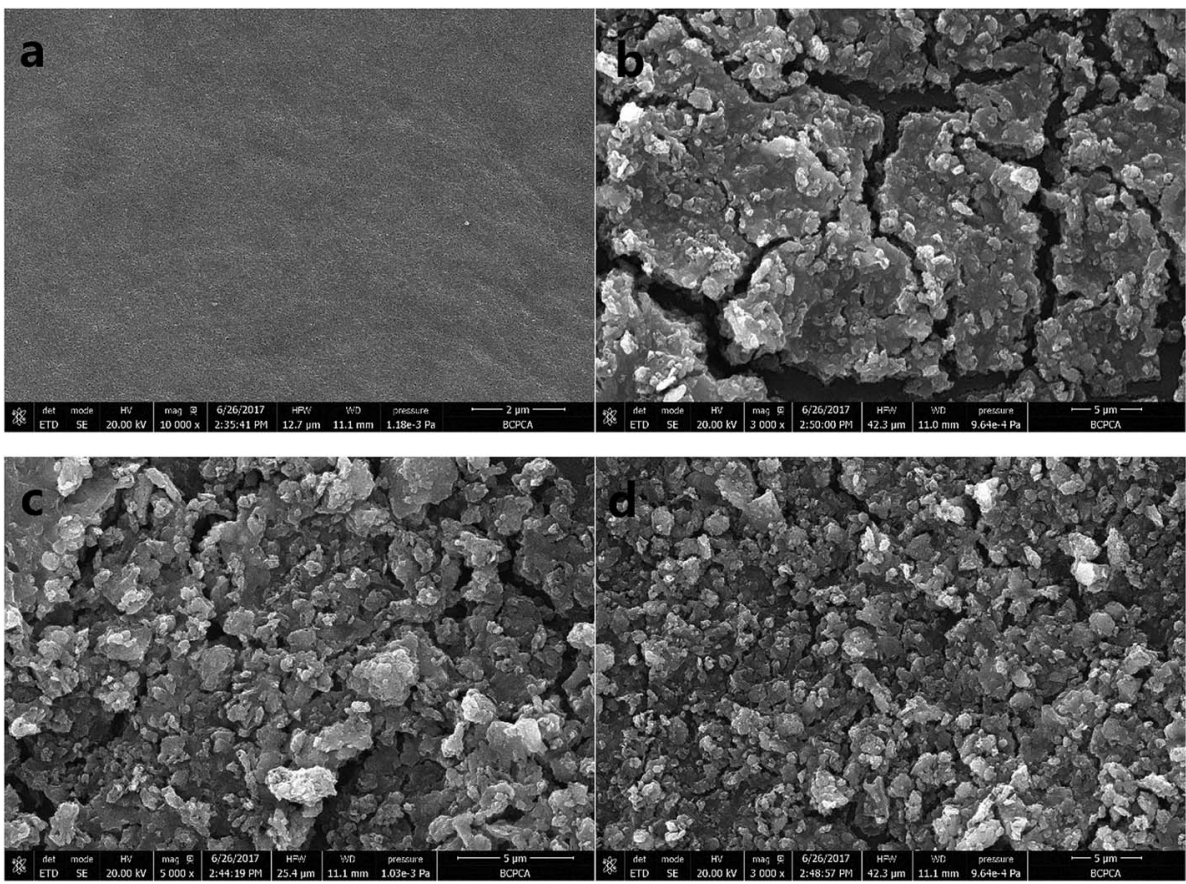

Fig. 7 SEM of the morphology of membrane surface. (a) New membrane; cake layer formed by (b) Zr-based salt flocs, (c) alum-based salt flocs and (d) PACl-based salt flocs.

available filtration area when Zr salt flocs (larger size, compared with $\mathrm{Al}$ salt flocs) firstly deposited on the membrane surface. ${ }^{48}$ And then, in this case, the relative rapid flux decline during the initial filtration volume of $150 \mathrm{~mL}$ (Fig. 6a) can be attributed to the reduced available membrane area under a constant filtration pressure. While for the cake layers shown in Fig. 7c and d, more compact structures were easily found, since flocs with small size distribution are more likely to form a more compact cake layer and thus enhance the value of $R_{\mathrm{c}} \cdot{ }^{49}$ In addition, the higher concentration of HA of low and medium MW fractions remained in the water coagulated by Al salts (Fig. 1d) might cross the cake layer and result in shrinkage of flow channel caused by absorbed into membrane pores. The both aforementioned reasons were also expected to explain the continuous decreased membrane flux filtered by coagulated water containing Al salt flocs (Fig. 6a). Consequently, it can be concluded that the Zr-based coagulant is more effective in membrane fouling control, compared with Al-based coagulants.

\section{Conclusions}

The main conclusions of this work are as below:

(1) The $\mathrm{Zr}$ coagulant offers improved particulates and organics removal over traditional Al-based coagulants at neutral $\mathrm{pH}$ and at a room temperature $\left(25{ }^{\circ} \mathrm{C}\right)$. However, Al-based coagulants are less negatively influenced by the variation in $\mathrm{pH}$ and temperature.

(2) Flocs produced by the Zr coagulant are characterized by greater size, stronger strength, better recovery ability (nearly $100 \%$ ) and extraordinarily superior settleability.
(3) The $\mathrm{Zr}$ coagulant was observed to be more effective in membrane fouling control, especially in terms of irreversible fouling attributed to its better removal efficiency of low-medium MW humic acid.

(4) Further work should consider the application of $\mathrm{Zr}$ coagulants for membrane fouling control caused by other types of organic pollutants, e.g. polysaccharides and protein-like pollutants.

\section{Conflicts of interest}

There are no conflicts to declare.

\section{Acknowledgements}

This work was supported by National Natural Science Foundation of China (Grants 51478010).

\section{References}

1 Y. Liao, X. M. Tang, Q. Q. Yang, W. Chen, B. Z. Liu, C. L. Zhao, J. Zhai and H. L. Zheng, RSC Adv., 2017, 7, 19856-19862.

2 J. L. Lin, J. R. Pan and C. P. Huang, Sep. Purif. Technol., 2013, 115, 145-151.

3 J. Y. Shin, R. F. Spinette and C. R. O'Melia, Environ. Sci. Technol., 2008, 42, 2582-2589.

4 M. Q. Yan, D. S. Wang, J. R. Ni, J. H. Qu, Y. Yan and C. W. K. Chow, Sep. Purif. Technol., 2008, 62, 401-406.

5 W. Z. Yu, J. Gregory and L. C. Campos, Water Res., 2011, 45, 6718-6724. 
6 J. E. Vanbenschoten and J. K. Edzwald, J.-Am. Water Works Assoc., 1990, 82, 71-78.

7 E. Gauthier, I. Fortier, F. Courchesne, P. Pepin, J. Mortimer and D. Gauvreau, Environ. Res., 2000, 84, 232-246.

8 X. Huang, B. Y. Gao, Q. Y. Yue, Y. Wang and Q. Li, RSC $A d v$., 2016, 6, 24898-24905.

9 Y. X. Zhao, B. Y. Gao, B. C. Cao, Z. L. Yang, Q. V. Yue, H. K. Shon and J. H. Kim, Chem. Eng. J., 2011, 166, 544-550.

10 L. Chekli, C. Eripret, S. H. Park, S. A. A. Tabatabai, O. Vronska, B. Tamburic, J. H. Kim and H. K. Shon, Sep. Purif. Technol., 2017, 175, 99-106.

11 P. Jarvis, E. Sharp, M. Pidou, R. Molinder, S. A. Parsons and B. Jefferson, Water Res., 2012, 46, 4179-4187.

12 S. Hussain, J. van Leeuwen, C. W. K. Chow, R. Aryal, S. Beecham, J. M. Duan and M. Drikas, Chem. Eng. J., 2014, 254, 635-646.

13 P. Jarvis, M. Mergen, J. Banks, B. Mcintosh, S. A. Parsons and B. Jefferson, Environ. Sci. Technol., 2008, 42, 1276-1282.

14 D. Lakshmanan, D. Clifford and G. Samanta, J.-Am. Water Works Assoc., 2008, 100, 76-82.

15 B. Ayukawa, US Pat. 4066542, 1978.

16 S. Zhao, B. Y. Gao, S. L. Sun, Q. Y. Yue, H. Y. Dong and W. Song, Colloids Surf., A, 2015, 469, 235-241.

17 H. Xu, R. Y. Jiao, F. Xiao and D. S. Wang, Colloids Surf., A, 2016, 490, 189-199.

18 B. W. Ma, W. Z. Yu, H. J. Liu and J. H. Qu, Water Res., 2014, 51, 277-283.

19 T. Liu, Z. L. Chen, W. Z. Yu, J. M. Shen and J. Gregory, Water Res., 2011, 45, 4260-4268.

20 W. Z. Yu, Y. J. Yang and N. Graham, Chem. Eng. J., 2016, 298, 234-242.

21 W. Z. Yu, L. C. Campos and N. Graham, Water Res., 2016, 107, 83-92.

22 W. Z. Yu, N. J. D. Graham and G. D. Fowler, Water Res., 2016, 95, 1-10.

23 X. Huang, B. Y. Gao, S. Zhao, S. L. Sun, Q. Y. Yue, Y. Wang and Q. Li, RSC Adv., 2016, 6, 49469-49477.

24 X. Chen and H. P. Deng, Desalination, 2012, 300, 51-57.

25 W. Z. Yu, C. Z. Hu, H. J. Liu and J. H. Qu, Colloids Surf., A, 2012, 404, 106-111.

26 W. Z. Yu, J. Gregory, H. J. Liu and J. H. Qu, Colloids Surf., A, 2014, 443, 177-181.

27 J. M. Duan and J. Gregory, Adv. Colloid Interface Sci., 2003, 100, 475-502.
28 J. Gregory and H. Chung, Aqua, 1995, 44, 125-131.

29 B. Guo, H. Yu, B. Y. Gao, H. Y. Rong, H. Y. Dong, D. F. Ma, R. H. Li and S. Zhao, Colloids Surf., A, 2015, 481, 476-484.

30 R. K. Chakraborti, J. F. Atkinson and J. E. Van Benschoten, Environ. Sci. Technol., 2000, 34, 3969-3976.

31 M. Yao, J. Nan, T. Chen, D. Zhan, Q. G. Li, Z. B. Wang and H. Y. Li, J. Membr. Sci., 2015, 491, 63-72.

32 K. Li, H. Liang, F. S. Qu, S. L. Shao, H. R. Yu, Z. S. Han, X. Du and G. B. Li, J. Membr. Sci., 2014, 471, 94-102.

33 S. X. Duan, H. Xu, F. Xiao, D. S. Wang, C. Q. Ye, R. Y. Jiao and Y. J. Liu, Colloids Surf., A, 2014, 459, 14-21.

34 Z. Y. Su, X. Li and Y. L. Yang, Colloids Surf., A, 2017, 527, 109114.

35 L. Chekli, J. Galloux, Y. X. Zhao, B. Y. Gao and H. K. Shon, Sep. Purif. Technol., 2015, 142, 155-161.

36 Z. L. Zhang, C. D. Wu, Y. Wu and C. X. Hu, Environ. Sci. Pollut. Res., 2014, 21, 6632-6639.

37 Z. L. Yang, B. Y. Gao and Q. Y. Yue, Chem. Eng. J., 2010, 165, 122-132.

38 P. Y. Zhang, Z. Wu, G. M. Zhang, G. M. Zeng, H. Y. Zhang, J. Li, X. G. Song and J. H. Dong, Sep. Purif. Technol., 2008, 63, 642-647.

39 B. Corain, G. G. Bombi, A. Tapparo, M. Perazzolo and P. Zatta, Coord. Chem. Rev., 1996, 149, 11-22.

40 Z. W. Zhou, Y. L. Yang, X. Li, W. Gao, H. Liang and G. B. Li, J. Environ. Sci., 2012, 24, 1014-1020.

41 F. Xiao, J. Ma, P. Yi and J. C. H. Huang, Water Res., 2008, 42, 2983-2992.

42 W. Z. Yu, J. Gregory, G. B. Li and J. H. Qu, Chem. Eng. J., 2013, 223, 412-417.

43 J. C. Wei, B. Y. Gao, Q. Y. Yue and Y. Wang, Chem. Eng. J., 2009, 151, 176-182.

44 W. Z. Yu, J. Gregory, L. C. Campos and N. Graham, Water Res., 2015, 68, 119-126.

45 Z. B. Wang, J. Nan, M. Yao, Y. M. Yang and X. F. Zhang, J. Membr. Sci., 2017, 529, 80-86.

46 F. S. Qu, H. Liang, Z. Z. Wang, H. Wang, H. R. Yu and G. B. Li, Water Res., 2012, 46, 1490-1500.

47 B. Z. Dong, Y. Chen, N. Y. Gao and J. C. Fan, Desalination, 2006, 195, 201-208.

48 S. A. A. Tabatabai, J. C. Schippers and M. D. Kennedy, Water Res., 2014, 59, 283-294.

49 W. Z. Yu, T. Liu, J. Gregory, L. Campos, G. B. Li and J. H. Qu, J. Membr. Sci., 2011, 385, 194-199. 